\title{
Evaluation of Sugar Based Antidiarrheal Agent Versus Sugar Free Anti Diarrhoeal Preparation in Paediatric Diarrhoea
}

\author{
Dr. Avinash Shankar ${ }^{1 *}$, Dr Amresh Shankar ${ }^{2}$, Dr. Anuradha Shankar ${ }^{3}$ \\ ${ }^{1} M D$ (internal Medicine),DNB(E\&M);PhD Postgraduate in Endocrinology \& Metabolism (AIIMS-Delhi) \\ Chairman ,National Institute of Health \& Research Institute of Applied Endocrinology Warisaliganj (Nawada) \\ Bihar 805130, India. \\ ${ }^{2}$ BAMS (BRABU) MHA, Hon Director AarogyamPunarjeevan Ram Bhawan, Ara Garden Road, Jagdeopath, \\ Baily Road PATNA 14,800014, India. \\ ${ }^{3}$ BAMS (BRABU) Senior Research Fellow Regional Institute of Ayurveda, Itanagar (Arunachal Pradesh), India. \\ *Corresponding Author: Dr. Avinash Shankar, MD(internal Medicine),DNB(E\&M);PhD Postgraduate \\ in Endocrinology \& Metabolism (AIIMS-Delhi) Chairman, National Institute of Health \& Research Institute \\ of Applied Endocrinology Warisaliganj (Nawada) Bihar 805130, India.
}

\begin{abstract}
Lactose intolerance diarrhoea and increasing threat of Organo toxicity due to increasing non dietary constituents in the food and drinks, even contamination of milk poses problems in diarrhoea management in spite of big antidiarrheal armamentarium.

In addition for the sake of convenience even injudicious combination of potent antimicrobials and antiprotozoal being used inspite of FDA warnings.Thus in the context the present study to evaluate the sugar free Norfloxacin and Sugar free Tinidazole suspension administered separately in therapeutic dose proves worth as compared to sugar based norfloxacin and Tinidazole suspension separately or in combination as Sugar free Tinidazole and Sugar free Norfloxacin administered separately every 12 hours achieves remission without any untoward effects, drug related toxicity, relapse, recurrence and post therapeutic sequel even in neonates.
\end{abstract}

Keywords: Lactose intolerance, Organotoxicity ,FDA, relapse, untoward effects

\section{INTRODUCTION}

Diarrhoea remains a major killer inspite of available varied range of antidiarrhoel agents.In addition lactose intolerance diarrhoea and documented hazards of sugar based oral liquid preparation i.e.exacerbation of diarrhoeal presentation due to reversed mucosal transport of fluid and electrolytes in the intestine, poses threat in care of children diarrhoea .

Current study affirms clinical superiority of Tinidaazole - Norfloxacin over existing anti diarrhoeal in vogue though FDA declared either irrational or band.Thus with consideration a comparative clinical evaluation of Norfloxacin and Tinidazole liquid oral preparation in non-sugar base ,administered separately was planned to adjudge the therapeutic efficacy and safety profile .

\section{Material \& Methods}

Design of study: parallel group comparative study to determine the therapeutic status of sugar free Tinidazole and Norfloxacin oral liquid preparation administered separately with vigil watch on safety profile and drug compliance.

\subsection{Patients}

320 patients of diarrhoea presenting at Centre for Diarrhoeal Disease Research of National Institute of Health \& Research Warisaliganj (Nawada) Bihar were selected. Patients of fungal diarrhoea and helminthic diarrhoea been excluded from the study

\subsection{Methods}

Parent of the children under study were thoroughly interrogated for presenting features, duration and treatment taken ,their clinical response ,examined for clinical status and investigated for pathological status . 
Evaluation of Sugar Based Antidiarrheal Agent Versus Sugar Free Anti Diarrhoeal Preparation in Paediatric Diarrhoea

\section{Interrogated for - \\ Frequency and consistency of stool \\ Colour and smell of the stool \\ Relation with food \\ Any other presenting feature}

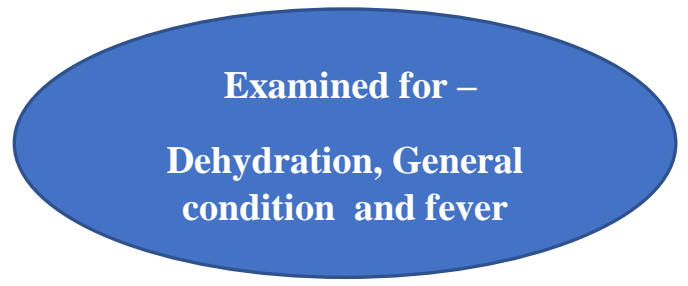

\section{Investigated For -}

- Causative pathogen,

- Urine culture and sensitivity

- Blod for Widal

- Stool routine

Based on clinicopathological status patients were graded as -

\begin{tabular}{|ll|}
\hline Grades of Severity & Characteristics \\
Mild & Irritable and thirsty \\
Moderate & irritable, pulse weak, reduced urine volume \\
& Depressed fontanelle, shunken eyes dry and \\
& pinched face, liips parched, dry buccal mucosa \\
& loss of skin turgor and thirsty \\
Severe & moribund, apathetic, signs of peripheral \\
& circulatory failure (cold and calm extremity decreased \\
& urine output) Depressed fontanelle, shunken eyes dry and \\
& pinched face, liips parched, dry buccal mucosa, loss of skin \\
& turgor and thirsty
\end{tabular}

For comparative analysis selected patients were classified in to three groups constituting equal number of patients i.e. Group A, Group B and Group C and were advocated the therapeutics as per follows Each group were administered Norfloxacin and Tinidazole oral preparation in various forms in therapeutic dose.

\begin{tabular}{|ll|}
\hline Graoup A: & $\begin{array}{c}\text { Sugar free Norfloxacin and Tinidazole suspension in separate } \\
\text { pack; Dose: } 0.5 \mathrm{ml} / \mathrm{kg} \text { both drug every } 12 \text { hours }\end{array}$ \\
Group B & $\begin{array}{c}\text { Sugar based norfloxacin and Tinidazole suspension separately in } \\
\text { dose of } 0.5 \mathrm{ml} / \mathrm{kg} \text { both drugs every } 12 \text { hours }\end{array}$ \\
Group C: & $\begin{array}{c}\text { Sugar based Norfloxacin and Tinidazole composite in dose of } \\
0.5 \mathrm{ml} / \mathrm{kg} \text { every } 12 \text { hours }\end{array}$ \\
\hline
\end{tabular}

\subsection{Assesment}

Clinical efficacy was assessed as per following index of assessment i.e.-

- Frequency and consistency of stool

- Dehydration status

- Duration of therapy

- Time required for clinical improvement

Post therapy status was assessed as per -

Patients were followed up for 4 weeks to asses -

- Any relapse, recurrence or persistence

- Urinary complaints and confirmation by urine culture and sensitivity

- Persistent pyrexia

- Hepato renal status by evaluating serum bilirubin ,SGOT,SGPT,Akaline phosphatase ,Blood urea,Serumcreatinine and urine albumin .

Based on the clinical response, therapeutic response was graded as - 
Evaluation of Sugar Based Antidiarrheal Agent Versus Sugar Free Anti Diarrhoeal Preparation in Paediatric Diarrhoea

\begin{tabular}{|ll|}
\hline Grades of clinical response & Characteristics \\
Grade I & Complete resolution of signs and \\
& symptom,formed stool,absence of tenesmus \\
& decrease in stool frequency ,absence of \\
& causative pathogenand drug relatd or post \\
& therapy after effects . \\
Grade II & improvement of signs and symptom without any absence of causative pathogens \\
Grade III & No response Or persistence of presenting \\
& feature and causative pathogens \\
\hline
\end{tabular}

\section{OBSERVATION}

Selected patients were of age group neonates to 5 years and among them 183 and 117 were male and female respectively and $31 \%$ patients were presenting with lose motion 10 per 12 hours (table -1, Fig 1)

Among the selected patients $48 \%$ were with mild dehydration ,28\% with moderate and $24 \%$ were with severe dehydration (Table -2)

Commonest isolated pathogen were Escheresia coli,salmonella ,Shigella and protozoa (Table -3)

Among the selected patients $52 \%$ were with associated vomiting though associated presentations like fever, abdominal colic ,abdominal dissension were also present (Table -4)

Table1. Distribution of patients as per age, sex and frequency of motion every 12 hours

\begin{tabular}{|l|c|c|c|c|c|c|c|c|}
\hline Age & \multicolumn{9}{|c|}{ Number of patients } \\
\hline Frequency of motion/12hrs & \multicolumn{2}{|c|}{$\mathbf{4 - 6}$} & \multicolumn{2}{|c|}{$\mathbf{7 - 9}$} & \multicolumn{2}{|c|}{$\mathbf{1 0 - 1 2}$} & \multicolumn{2}{c|}{$>12$} \\
\hline & Male & Female & Male & Female & Male & Female & Male & Female \\
\hline Up to 1 year & 24 & 12 & 9 & 6 & 9 & 6 & 6 & 3 \\
\hline $1-2$ & 18 & 9 & 12 & 9 & 9 & 6 & 6 & 6 \\
\hline $2-3$ & 21 & 9 & 9 & 6 & 6 & 6 & 3 & 3 \\
\hline $3-4$ & 15 & 9 & 9 & 6 & 3 & 3 & 3 & 3 \\
\hline $4-5$ & 12 & 6 & 3 & 3 & 3 & 3 & 3 & 3 \\
\hline
\end{tabular}

Pie diagram showing male female composition

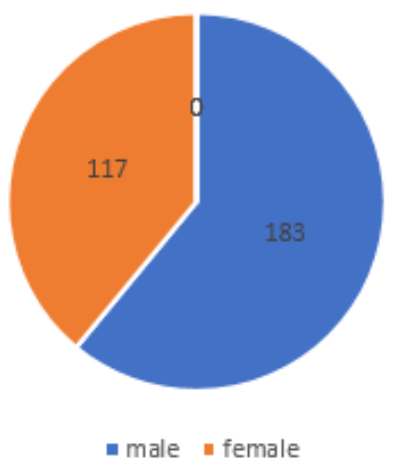

Fig1. Pie diagram showing male female composition

Table2. Shows distribution of patients as per associated clinical presentation

\begin{tabular}{|l|c|c|c|}
\hline \multirow{2}{*}{\multicolumn{1}{|c|}{ Associated presentations }} & \multicolumn{3}{c|}{ Number of patients } \\
\cline { 2 - 4 } & Male & Female & Total \\
\hline Pain in abdomen & 40 & 27 & 67 Bar diagram showing \\
\hline Vomiting & 42 & 28 & 70 \\
\hline Fever & 24 & 15 & 39 \\
\hline Vomiting \& pain in abdomen & 24 & 14 & 38 \\
\hline Vomiting \& Fever & 14 & 8 & 22 \\
\hline Vomiting, Fever and pain in abdomen & 24 & 14 & 38 \\
\hline Pain in abdomen \& Fever & 15 & 11 & 26 \\
\hline
\end{tabular}


Evaluation of Sugar Based Antidiarrheal Agent Versus Sugar Free Anti Diarrhoeal Preparation in Paediatric Diarrhoea

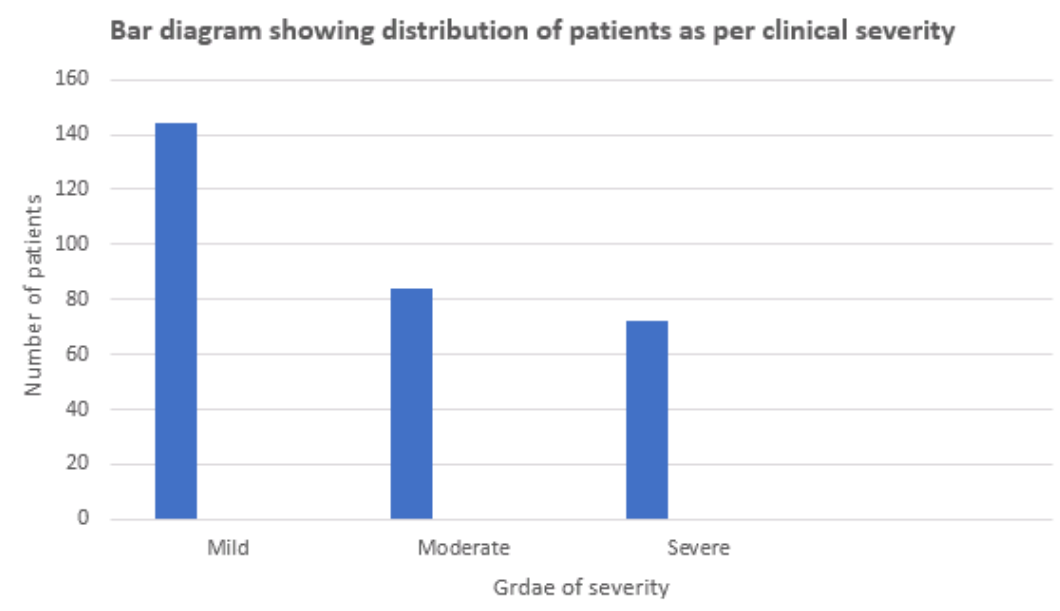

Figure2. Bar diagram showing distribution of patients as per degree of severity

Table3. Distribution of patients as per isolated causative pathogen

\begin{tabular}{|l|r|r|r|}
\hline \multirow{2}{*}{\multicolumn{1}{|c|}{ Isolated causative pathogen }} & \multicolumn{3}{c|}{ Number of patients } \\
\cline { 2 - 5 } & Male & Female & Total \\
\hline Escherichia coli \& Protozoa & 21 & 12 & 33 \\
\hline Shigella \& Protozoa & 42 & 24 & 66 \\
\hline Salmonella \& protozoa & 51 & 30 & 81 \\
\hline Salmonella & 30 & 21 & 51 \\
\hline Shigella & 21 & 18 & 39 \\
\hline Escherichia coli & 18 & 12 & 30 \\
\hline
\end{tabular}

Table4. Outcome of the study

\begin{tabular}{|l|c|c|c|}
\hline Particulars Clinical cure: & Group A & Group B & Group C \\
\hline Grade I & $100 \%$ & $82 \%$ & $56 \%$ \\
\hline Grade II & - & $14 \%$ & $32 \%$ \\
\hline Grade III & - & $4 \%$ & $12 \%$ \\
\hline Pathological cure : & \multicolumn{3}{|c|}{} \\
\hline Sterile sample & $100 \%$ & $82 \%$ & $56 \%$ \\
\hline Presence of pathogen & - & $18 \%$ & $44 \%$ \\
\hline Fungal super infection & - & $9 \%$ & $16 \%$ \\
\hline Adjuvant required & None & $18 \%$ & $44 \%$ \\
\hline Dehydration exacerbation & None & $18 \%$ & $42 \%$ \\
\hline Oliguria & None & $7 \%$ & $22 \%$ \\
\hline Therapy related untoward effects: & & & \multicolumn{2}{|c|}{$28 \%$} \\
\hline Abdominal distension & None & $14 \%$ & $30 \%$ \\
\hline Vomiting & None & $10 \%$ & $6 \%$ \\
\hline Irritability & None & $15 \%$ & \\
\hline Post therapy sequel & \multicolumn{3}{|l|}{} \\
\hline Urinary tract infection & None & $12 \%$ & $20 \%$ \\
\hline Mucous colitis & None & $6 \%$ & $9 \%$ \\
\hline Diarrhoeal persistence & None & $2 \%$ & $7 \%$ \\
\hline
\end{tabular}

\section{RESUlTS}

All patients on sugar free Tinidazole and Norfloxacin oral liquid administered separately achieved grade I clinical response whether only $82 \%$ of group B and $56 \%$ of group C respectively.

All patients of group A had absence of causative pathogens without any persistence of infection or super infection

None of group A required any adjuvant therapy or had any exacerbation of dehydration while 18 and 44 of group B and group C respectively required adjuvant therapy whether 18 and 42 of group B and group $\mathrm{C}$ respectively had exacerbation of dehydration requiring intravenous supplementation.

07 and 22 of group B and group C respectively had oliguria ,in addition 14 and 28 patients of group B and group $\mathrm{C}$ had abdominal distension , 10 and 30 had vomiting ,15 and 16 had irritability, 12 and 20 
had UTI ,06 and 09 mucous colitis , 02 and 07 with persistent diarrhoea respectively, though none of the group A had any such complaints.

\section{DISCUSSION}

Diarrhoea a most common treatable children killer disease and increasing non dietary constituents in the food stuff possess problems like hyperglycemic syndromedue to declined hepatopancreatic function as a result of organotoxicity in addition sugar promotes microbial growth, increases hepatic overload and norfloxacin a least absorving quinolone and Tinidazole a potent antiprotozoal, a known anti diarrhoeal.

Present comparative clinical study of sugar free Tinidazole and Norfloxacin oral liquid administered separately as compared to sugar based norfloxacin and tinidazole either separately or in combination reveals clinical superiority over the sugar based preparation as This achieves complete clinical and pathological cure in minimum duration without any adjuvant, untoward effects either during therapy or in post therapy period whether only $82 \%$ and $56 \%$ of group B and group C respectively had grade I clinical response though relapse, untoward effects and adjuvant is required in the patients of group B and group $\mathrm{C}$. and this marked difference suggest clinical superiority of sugar free oral anti diarrhoeal preperation may be due to varied bio availability of the anti-diarrhoeal composit or increased virulence of the causative pathogen.

In addition, sugar base may cause altered drug concentration acting on the intestinal microbes and marked exacerbation of dehydration, persistence of causative pathogens and super infection, altered antimicrobial absorption, thus induces development of resistant strain resulting in post therapy UTI, mucous colitis, persistence of causative pathogens and exacerbation of presenting symptoms. in addition, altered intestinal $\mathrm{pH}$ results in excessive fermentation and gaseous distension of abdomen and reflux nausea.

Hence conclusively to check diarrhoea in children sugar free antidiarrhoel preparation to be used separately in therapeutic dose.

\section{CONClusion}

Sugar free oral liquid preparation of Tinidazole and Norfloxacin in dose of Tinidazole $15 \mathrm{mg} / \mathrm{Kg}$ and Norfloxacin $10 \mathrm{mg} / \mathrm{Kg}$ every 12 hours administered separately proves worth in children's diarrhoea management

\section{REFERENCES}

[1] Shankar A; Advances in management of paediatric diarrhoea, presented at International update on diarrhoeal disease management

[2] Shankar A, Norfloxacin and Tinidazole in management of Paediatric diarrhoea, The Antiseptic 97:10:357$360 / 2000$

[3] Shankar A, Comparative evaluation of sugar free versus sugar based oral liquid preparation in Medicare Acta Scientific Nutritional Health volume 3 issue 8, August 2019.

[4] Walsh JA, Warren KS. Selective primary health care: an interim strategy for disease control in developing countries. N Engl J Med. 1979 Nov 1;301(18):967-974. [PubMed] [Google Scholar]

[5] DeWitt TG, Humphrey KF, McCarthy P. Clinical predictors of acute bacterial diarrhea in young children. Pediatrics. 1985 Oct;76(4):551-556. [PubMed] [Google Scholar]

[6] Portnoy BL, DuPont HL, Pruitt D, Abdo JA, Rodriguez JT. Antidiarrheal agents in the treatment of acute diarrhea in children. JAMA. 1976 Aug 16;236(7):844-846. [PubMed] [Google Scholar]

Citation: Dr. Avinash Shankar, et.al. (2019). "Evaluation of Sugar Based Antidiarrheal Agent Versus Sugar Free Anti Diarrhoeal Preparation in Paediatric Diarrhoea”. International Journal of Clinical Chemistry and Laboratory Medicine (IJCCLM), 5(3), pp.1-5, DOI: http://dx.doi.org/10.20431/2455-7153.0503001.

Copyright: () 2019 Authors. This is an open-access article distributed under the terms of the Creative Commons Attribution License, which permits unrestricted use, distribution, and reproduction in any medium, provided the original author and source are credited. 